\title{
A REVOLUÇÃO DE 1930 E O DIREITO DO TRABALHO NO BRASIL
}

\author{
Otavio Pinto e Silva \\ Professor Assistente do Departamento de Direito do Trabalho \\ da Faculdade de Direito da Universidade de Sāo Paulo
}

\begin{abstract}
Resumo:
A formação do Direito do Trabalho brasileiro é marcada pela forte intervenção estatal, em especial após a ascensão de Getúlio Vargas ao poder, tendo em vista os acontecimentos da chamada "Revolução de 1930" O presente estudo busca demonstrar a relação existente entre o movimento revolucionário e a instauração do modelo corporativista no Brasil.
\end{abstract}

Abstract:

The constitution of the Brazilian Labor Law is characterized by a strong state intervention, especially after Getúlio Vargas ascended to the presidency, in view of the events concerning the so-called "Revolution of 30" This study aims at demonstrating the relationship between the revolutionary movement and the establishment of the corporatist model in Brazil.

Unitermos: história do Direito do Trabalho; corporativismo; organização sindical.

\section{Introdução}

O estudo da história do Direito do Trabalho no Brasil não pode prescindir do exame do papel desempenhado pelos agentes do movimento revolucionário de 1930 , na medida em que foi a partir de então que se intensificou de maneira marcante a intervenção estatal na regulamentação das condições de trabalho, com o surgimento de um sem-número de leis trabalhistas.

As conseqüências da Revolução de 1930 para o Direito do Trabalho brasileiro, assim, devem ser analisadas em vista da instauração dos alicerces para a construção de um modelo jurídico que ficou conhecido como o "corporativismo" cujas marcas podem ainda hoje ser encontradas.

O presente trabalho, portanto, avalia a relação existente entre a Revolução de 1930 que encerrou com um período histórico do Brasil conhecido como a "República Velha" e u surgimento de um novo Estado, cuja principal 
característica, na área do Direito do Trabalho, é a de um acentuado intervencionismo (por meio do qual se dizia que seria possível superar os conflitos de classes, tudo em nome do interesse da nação).

Assim, são expostos os fatores econômicos, sociais e políticos que levaram à Revolução de 1930 e em seguida são analisadas as conseqüências do movimento revolucionário, demonstrando como se deu a instauração do modelo corporativista.

\section{A Revolução de 1930}

O estudo histórico dos elementos que propiciaram as condições necessárias para o êxito do movimento revolucionário de 1930 deve ser efetuado tendo em vista a conjunção de diversos fatores.

Em primeiro lugar, é preciso inserir o Brasil dentro de uma ordem econômica mundial marcada pela recessão: em 1929, o "crack" da Bolsa de Nova York trouxe consequiências desastrosas para o país, que ainda vivia uma industrialização incipiente e possuía um sistema econômico totalmente dependente das exportações do café. A queda da cotação dos preços de seu produto de maior importância no mercado internacional logicamente colocou o Brasil em uma situação nada confortável.

No campo político, constata-se o esgotamento de um sistema que ficou conhecido como o "café com leite" por meio do qual mineiros e paulistas se revezavam na Presidência da República.

Em 1922, o mineiro Artur Bernardes elegeu-se presidente enfrentando, já durante a campanha, uma forte oposição militar que, posteriormente, se perpetuaria durante o seu governo: quase todo o seu mandato escoou-se sob o estado de sítio. A candidatura derrotada de Nilo Peçanha denunciava o arranjo político São Paulo-Minas Gerais como uma forma de garantir recursos para os esquemas de valorização do café.

A influência do movimento militar conhecido como "tenentismo" foi uma das marcas dos anos 20. As soluções revolucionárias se apresentaram com desenvoltura, e as transformações do pensamento anarquista (fortemente influenciado pelos imigrantes) levaram as lideranças operárias a novas formas organizatórias e políticas.

Para as camadas intermediárias e populares da sociedade, os tenentes representavam a esperança de uma alteração da ordem vigente, com melhorias nos 
salários e nas condições de moradia, além de maiores direitos políticos; para as classes dominantes regionais, em oposição ao núcleo agrário-exportador, surgia a possibilidade de utilizar a violência para reformar o Estado.

A Coluna Prestes se movimentava pelo sertão brasileiro, pregando ideais revolucionários e obrigando Artur Bernardes a utilizar medidas de força para tentar impedir os seus avanços. O número de presos e exilados foi enorme.

Mas, apesar das dificuldades, a sucessão presidencial se fez da forma planejada pelo então presidente, constituindo-se a "expressão da continuidade do domínio oligárquico" ' com a eleição do paulista Washington Luis, que tomou posse em 15 de novembro de 1926 sob uma expectativa favorável da população.

Logo, porém, frustraram-se as esperanças nos projetos de anistia, que eram sempre combatidos pelo Governo. Daí a permanência de uma persistente ameaça revolucionária por parte do movimento tenentista, cujos principais líderes se encontravam no Exterior, principalmente em Buenos Aires e Montevidéu.

Por outro lado, movimentos oposicionistas se intensificaram em determinadas regiōes, em especial naquelas em que oligarquias locais não concordavam com a política administrativa e financeira em defesa do café levada a cabo pelo presidente.

Chegado o momento de nova sucessão presidencial, viu-se o surgimento de dificuldades para a obtenção de uma nova fórmula com boa aceitação nacional.

A volta de Minas Gerais ao poder, por meio de Antonio Carlos Ribeiro de Andrada, parecia o caminho normal de acomodação das forças políticas.

Entretanto, a intransigência de Washington Luis alterou os rumos do acordo tácito até então vigente: o presidente, desprezando o "café com leite" preferiu lançar a candidatura de Júlio Prestes, presidente do Estado de São Paulo.

Isso fez com que Minas buscasse uma composição com o Rio Grande do Sul para enfrentar o candidato oficial: criada a Aliança Liberal, o presidente do Estado gaúcho, Getúlio Vargas (ex-ministro da Fazenda do próprio Washington Luis) foi escolhido como o candidato da oposição, sustentando um programa que refletindo as aspirações das classes dominantes regionais não-associadas ao setor cafeeiro - tinha por objetivo sensibilizar a classe média. 401.

1. Carone, Edgard. A República Velha II (Evolução Política), DIFEL, Rio de Janeiro, 1977, p. 
Assim, defendia a necessidade de se incentivar a produção nacional em geral e não apenas o café; e em uma evidente resposta ao presidente que teria afirmado ser a questão social no Brasil "um caso de polícia" ${ }^{2}$ a plataforma da Aliança Liberal acenava com algumas medidas de proteção aos trabalhadores (extensão da aposentadoria, regulamentação do trabalho da mulher e do menor, aplicação da lei de férias) ao mesmo tempo em que fazia a defesa das liberdades individuais, da anistia (em claro apelo aos tenentes) e da reforma política.

Apurados os votos, Júlio Prestes obteve 1.091 .709 do total de 1.890.524 votos, sendo que a oposição recusou os resultados oficiais. ${ }^{3}$ Entretanto, a princípio não se pensou em uma resposta armada, pois os principais líderes aliancistas temiam o revide pós-eleitoral: o passado comprovava fartamente que todas as rebeldias contra os governos federais levavam a conflitos e pressões, na forma do incitamento de revoluções nos Estados e até de embargos econômicos. Estava bem fresca na memória de todos a resposta dada por Artur Bernardes aos seus adversários da Reação Republicana, e Washington Luis dava mostras, no momento, da determinação em prosseguir idêntica política.

O assassinato de João Pessoa, ocorrido em 25 de julho de 1930 na Paraiba ele que havia sido candidato a vice-presidente na chapa da Aliança Liberal -, teve um efeito traumático, fazendo com que os mais radicais conseguissem criar uma atmosfera revolucionária, convencendo alguns recalcitrantes, como o próprio Getúlio Vargas e Antonio Carlos.

Consoante lição de Edgard Carone, o que se deu com as eleições de março de 1930 foi "um dissídio momentâneo das oligarquias, que conduz a conseqüências extremas, devido, em parte, às soluções radicais e revolucionárias existentes no momento. Sem o fracionamento cada vez maior das oligarquias dominantes grupos dissidentes dos Estados e formação da Aliança Liberal o maior descontentamento das classes médias urbanas e a formação de uma elite revolucionária os tenentes - a revolução seria impossivel" ${ }^{4}$

Assim é que foi se formando um caldo de cultura favorável ao movimento conspiratório, até ser fixada a data de 03 de outubro para o início da

2. Fausto, Boris. A Revolução de 1930, Editora Brasiliense, São Paulo, 1991, p. 44.

3. Skidmore, Thomas. Brasil: de Getúlio a Castelo, Paz e Terra, Rio de Janciro, 1979, p. 22.

4. Carone, Edgard. Ob. cit., p. 421. 
revolta, que a princípio parecia ser conduzida apenas pelos políticos da Aliança Liberal (Minas Gerais, Paraíba, Rio Grande do Sul) e pelos tenentes.

Mas muitos oficiais de patente mais elevada alarmaram-se com as perspectivas de uma guerra civil de grandes proporções, a ponto de o chefe do Estado-Maior do Exército, general Tasso Fragoso, passar a apoiar os dissidentes, responsabilizando o presidente pelo estado de inquietação e desconfiança em que se encontrava o Pais. ${ }^{5}$

Os militares chegaram a lançar um manifesto por meio do qual pediam a renúncia de Washington Luis, mas este insistia em resistir, pretendendo entregar 0 poder ao presidente eleito, Júlio Prestes, em novembro.

A solução de força, então, se impôs: o presidente foi afastado e uma Junta Militar assumiu o Governo durante dez dias, para entregá-lo a Getúlio Vargas em 03 de novembro de 1930.

Nas palavras do brasilianista Thomas Skidmore, "a mudança de liderança política, resultante da ascensão de Vargas à Presidência, tornou-se conhecida como a Revolução de 30. Os acontecimentos posteriores confirmaram a precisão da denominação, pelo menos na esfera política. Na década e meia depois de Vargas ter assumido o poder, praticamente todas as características do sistema político e da estrutura administrativa foram objeto do zelo reformista" ${ }^{6}$

E é exatamente dentro deste contexto que se insere a questão do corporativismo. A década de 30 se mostra como a da transformação do Estado brasileiro, em que o direito de organização se transmuda em meio de identidade entre poder e sociedade: a ação pública vem para "resolver" as desigualdades, reconhecendo e controlando os direitos de participação e conciliando os interesses divergentes.

Como analisa Maria Célia Paoli, “o que ficou conhecido como a Revolução de 1930 marca o momento inicial da emergência de uma nova forma de exercício do poder político no país, embora esse novo possa ser infinitamente interrogado pelos historiadores do período, buscando nomear seu sentido. Conjunção múltipla de conflitos e projetos gerados diferencialmente desde o começo do século, a Revolução de 30 unificou-se aparentemente apenas no seu desenlace. E este foi a emergência de um Estado forte e autoritário, relativamente

5. Skidmore, Thomas. Ob. cit., p. 24.

6. Idem, p. 25. 
autonomizado das classes e grupos sociais de interesse, interventor minucioso na vida social, reabsorvendo suas diferenças e conflitos e produzindo sua própria significação como foco dinâmico da sociedade" ${ }^{7}$

Feito o exame acerca da Revolução de 1930, podemos agora passar à segunda parte deste trabalho e analisar então a instauração do corporativismo no Brasil e o seu significado.

\section{III - O Corporativismo}

A teoria corporativista surge tendo como ponto de partida uma constatação: a desorganização da vida econômica nas sociedades modernas estava estreitamente ligada com a realidade da luta de classes.

Na óptica corporativista, a luta de classes existe não em função dos interesses conflitantes entre a burguesia e o proletariado, mas sim diante da ausência de leis que regulem a atividade econômica.

Assim, o corporativismo surge para deslocar de posição a idéia da luta de classes, afirmando que esta se dá não pela existência do capitalismo como pensava Marx mas sim por um erro jurídico do liberalismo, que em nome da liberdade do indivíduo deixa de limitar as paixões e os egoísmos.

A teoria corporativista, portanto, se apresenta como uma contraposição ao socialismo e também ao liberalismo: a verdadeira liberdade se expressa na autoridade e na racionalidade das leis que limitem os excessos dos indivíduos. Os grupos passam a ser valorizados, mas não quaisquer grupos: é preciso substituir a noção de "classes". pela das "corporações"

Trata-se de uma proposta de reordenação da sociedade, em que patrões e trabalhadores formam um só grupo, cujo superior interesse é a defesa da profissão. $\mathrm{O}$ regulamento das condições de trabalho dessa profissão, assim, deve ser definido tendo em vista laços de solidariedade, harmonia e colaboração, visando com isso resolver todos os conflitos que possam surgir dentro do grupo.

Nesse contexto, e com base em tais idéias, é que se insere a atuação do Governo instaurado no Brasil com a Revolução de 1930.

O Decreto n. 19.398 (de 11 de novembro de 1930) instituiu o Governo Provisório da República, que se investiu, em sua plenitude, das atribuições não-só do

7. Paoli, Maria Celia. A Era do Estado, arligo publicado no Folhetim, caderno do jornal Folha de S. Paulo, 31.12.88, p. G-4. 
Poder Executivo, mas também do Poder Legislativo, até que se reorganizasse o País a partir da eleição de uma Assembléia Constituinte.

Uma das primeiras medidas tomadas pelo Governo Provisório, então, foi a criação do Ministério do Trabalho (Decreto n. 19.433, de 26 de novembro de 1930), com amplas atribuições: cabia-lhe, segundo lição de Evaristo de Moraes Filho, "as funções de elaboração, aplicação e fiscalização das novas leis trabalhistas" ${ }^{8}$ funções estas cumpridas com bastante afinco, tanto que "de 1930 a 1934, até a promulgação da nova Constituição Federal, criou-se a toque de caixa, por necessidade, toda uma nova estrutura legal e administrativa para as coisas do trabalho: sindicalização, reforma das Caixas, nacionalização do trabalho, duração do trabalho, Comissões Mistas de Conciliação, Juntas de Conciliação $e$ Julgamento, carteira profissional, convenção coletiva, trabalho de mulheres e menores, férias, reforma do Conselho Nacional do Trabalho, Delegacia do Trabalho Marítimo, criação dos primeiros Institutos de Previdência, etc. Nesta época, ao contrário do que diz algum autor nacional, muito representaram na formação e cristalização do novo direito os despachos do Ministro do Estado, os pareceres do Consultor Jurídico e as decisões das Juntas, das Comissões Mistas e das autoridades administrativas do próprio Ministério. Cognominado, ora de fascista, ora de comunista, mal compreendido por muitos, coube ao Ministério do Trabalho, neste periodo e depois dele, papel relevantissimo na conquista definitiva de um Estado de direito social, ou seja, de bem-estar para o trabalhador, dentro, é claro, das limitações e de todos os percalços nacionais" ${ }^{9}$

O que se nota, portanto, é que houve um imenso esforço do Governo Revolucionário no sentido de consolidar uma nova estrutura de relações de trabalho. Buscou-se organizar a sociedade, atribuindo papéis específicos para os trabalhadores, os empregadores e o próprio Estado: cada parte da sociedade deveria adquirir uma função pública a cumprir.

Comentando essa nova estrutura então instalada no Brasil, Kazumi Munakata tece as seguintes considerações: "A presença do Estado é justificada como um meio de equilibrar a relação entre o patrão e o trabalhador, que, sob o liberalismo, caracterizava-se pela desigualdade real, escamoteada pela igualdade

8. Moraes Filho, Evaristo de. Introdução ao Direito do Trabalho, Editora LTr, São Paulo, 1986. p. 161.

9. Idem, pp. 161-162. 
formal de ambos perante a lei. Em outras palavras, o corporativismo, ao propor a intervenção estatal nas relações de trabalho, redefine também as noções de igualdade e de lei. A legislação trabalhista, para o corporativismo, é um instrumento que o Estado dispõe para que seja instaurada a verdadeira igualdade. Nesse sentido, a lei não deve ser igual para todos, mas explicitamente favorável aos mais fracos: 10

Ou seja, o conjunto de reformas exigidas pela Revolução de 1930 não poderia deixar de levar em consideração a chamada "questão social" tendo em vista uma verdadeira igualdade, de maneira que se fazia imprescindível a intervenção do Estado, para traçar os novos rumos a tomar.

Interessante notar, assim, como foi evoluindo o tratamento legislativo reservado à questão da organização sindical, tendo em vista os objetivos da Revolução.

Por meio do Decreto n. 19.770 , de 19 de março de 1931, se estabeleceu que todas as classes que exercessem "profissões identicas, similares ou conexas" poderiam defender perante o Governo da República, por intermédio do Ministério do Trabalho, os seus "interesses de ordem econômica, jurídica, higiênica e cultural"

Nas palavras de Joaquim Pimenta, referido Decreto foi "uma espécie de carta constitucional que, enquanto restaurava e garantia o direito de associação dos trabalhadores, ampliava o tipo tradicional do sindicato, que, além de instituição cujos estatutos ainda se regulavam por normas de direito privado, passava, também, a ser colaborador do Estado na solução de problemas diretamente ligados aos interesses da classe" 11

Em verdade, o Direito Sindical brasileiro, a partir da Revolução de 1930, passa por uma mudança de rumos, em tudo forjada pelo Governo. Antes, os sindicatos eram pessoas jurídicas de Direito Privado; a partir de 1931, passam a ser tidos como órgãos de colaboração do Governo, em evidente publicização, tanto que dependiam do reconhecimento do Estado para seu funcionamento, sendo certo, ainda, que somente poderiam se organizar sob a forma de categorias, delimitadas segundo um rígido plano de enquadramento sindical. Adotou-se o princípio da

10. Munakata, Kazumi. A Legislação Trabalhista no Brasil; Editora Brasiliense, São Paulo, 1981. pp. 70-71.

11. Pimenta, Joaquim. Sociologia Econômica c Jurídica do Trabalho, Livraria Frcitas Bastos. Rio de Janeiro, 1957, p. 191. 
unicidade sindical, por meio do qual só se admitia a formação de um único sindicato para representar os interesses de cada categoria profissional, na mesma base territorial.

Com a Constituição de 1934 tentou-se uma mudança, já que esta, no seu art. 120, acolheu o princípio da pluralidade sindical. O Decreto n. 24.694, promulgado um pouco antes da nova Carta, facultava a criação de mais de um sindicato na mesma base.

Porém, tal experiência não chegou a render frutos, e em 1937 foram restabelecidas as diretrizes de 1931, aumentando ainda mais o dirigismo estatal no meio sindical.

A Constituição de 1937 instituiu a organização corporativa da ordem econômica, dispondo em seu art. 140 que "a economia da produção será organizada em corporações e estas, como entidades representativas das forças do trabalho nacional, colocadas sob a assistência e a proteção do Estado, são órgãos deste $e$ exercem funções delegadas do poder público"

Cabia, assim, a um Conselho de Economia Nacional (órgão composto de representantes dos ramos da produção, indicados pelos sindicatos) as funções de promover a organização corporativa da economia nacional, bem como de estabelecer normas reguladoras dos contratos coletivos de trabalho.

Apesar de proclamar ser livre a associação sindical ou profissional, em verdade essa liberdade sofreu restrições na própria Constituição, uma vez que o seu art. 138 previa que "somente o sindicato regularmente reconhecido pelo Estado tem o direito de representação legal dos que participarem da categoria de produção para a qual foi constituido, e de defender-Ihes os direitos perante o Estado e as outras associações profissionais, estipular contratos coletivos de trabalho obrigatórios para todos os seus associados, impor-Ihes contribuições e exercer em relação a eles funções delegadas de poder público".

O modelo sindical estruturado, assim, não era permissivo, mas restritivo. Com a imposição do sindicato único na mesma base territorial, não houve liberdade para a criação de entidades. Forjou-se um sistema em que os sindicatos exerciam funções delegadas pelo poder público, e exatamente por isso podiam cobrar contribuições.

A organização se dava na forma de pirâmide: sindicatos, federações e confederações, componentes da corporação, possuidora de um poder regulamentar 
sobre toda a categoria, por meio do qual ditavam-se as normas e condições de trabalho aplicáveis a todos os seus integrantes.

Com essas medidas, como bem ressalta Amauri Mascaro Nascimento, "procurou o Estado ter em suas mãos o controle da economia nacional, para melhor desenvolver os seus programas. Para esse fim julgou imprescindível evitar a luta de classes; dai a integração das forças produtivas: os trabalhadores, empresários e profissionais liberais, numa unidade monolítica e não em grupos fracionados, com possibilidades estruturais conflitivas" 12

O Decreto n. 1.402, de 05 de julho de 1939, veio complementar a Carta de 1937, no plano da legislação ordinária. Fez uma distinção entre associações profissionais e sindicatos, permitindo a pluralidade de associações, mas exigindo o reconhecimento por parte do Ministério do Trabalho para que uma associação pudesse se transformar em sindicato. Foi instituído um quadro de atividades e profissões, previu-se a possibilidade de intervenções nos sindicatos, fixou-se regras sobre a administração dos mesmos.

A greve e o lock-out foram proibidos, considerados pela Constituição como "recursos anti-sociais, nocivos ao trabalho e ao capital e incompatíveis com os superiores interesses da produção" Para a solução dos conflitos entre o capital e o trabalho, criou-se a Justiça do Trabalho.

O que se percebe com esse emaranhado de medidas é a forte influência exercida pelo exemplo italiano. A "Carta del Lavoro" de 30 de abril de 1927, já tinha estabelecido os parâmetros para a organização do Estado Corporativo Fascista, em tudo semelhantes aos que foram transpostos para o Brasil.

Cesarino Júnior admite a influência da Itália na instauração do corporativismo brasileiro, mas constata algumas diferenças que, para ele, seriam fundamentais. Assim, afirma que o modelo brasileiro teria um caráter solidarista, ao proteger o trabalho como meio de subsistência do indivíduo" enquanto o italiano evidenciaria um caráter totalitário, ao tutelar o trabalho apenas e tão-somente a título de um "dever social" 13

De qualquer forma, é inegável que tanto o corporativismo brasileiro quanto o italiano acabaram servindo como instrumentos de dominação política.

12. Nascimento, Amauri Mascaro. Direito Sindical, Editora Saraiva, São Paulo, 1991, p. 68.

13. Cesarino Junior, A. F. Direilo Social Brasileiro, Editora Saraiva, 1970, p. 82. 
E foi dentro deste contexto que, em 1943, foi publicada a Consolidação das Leis do Trabalho CLT, reunindo as diversas normas trabalhistas então existentes.

Como ressalta Arion Sayão Romita, em conhecida obra sobre o Direito Sindical brasileiro, "em sua quase totalidade, os dispositivos do Decreto $n$. 1.402 foram incorporados à Consolidação das Leis do Trabalho, aprovada pelo Decreto-lei $n$. 5.452, de 01 de maio de 1943, de sorte que a organização por ele imposta permaneceu substancialmente a mesma, pois as alterações posteriores do texto consolidado não atingiram sua estrutura básica" ${ }^{14}$

Conclui-se, assim, que toda a organização sindical brasileira efetuouse, a partir da Revolução de 1930, tendo em vista ideais corporativistas, que condicionaram a evolução do nosso Direito do Trabalho.

Tão-fortes foram esses ideais que, até hoje, o Brasil possui uma estrutura, no campo das relações do trabalho, portadora de traços nitidamente corporativistas, que não foram jamais abandonados.

\section{Conclusão}

O exame do modelo de corporativismo implantado no Brasil passa, necessariamente, pelo estudo das condições históricas vividas nos anos 30 .

Evidentemente, o Governo que ascendeu ao poder com a Revolução de 1930, liderado por Getúlio Vargas, inspirou-se na experiência italiana para construir instrumentos de dominação política, buscando organizar as forças econômicas em torno do Estado.

A concepção corporativista, solidificada por meio da Constituição de 1937 baseava-se nas seguintes linhas fundamentais: a. organização corporativista da economia, com a constituição de órgãos representativos do capital e do trabalho, em forma piramidal, sob a supervisão do Estado; b. delegação de poderes a tais órgãos, para que estes se tornassem os representantes de categorias profissionais e celebrassem, em nome delas, contratos coletivos de trabalho; c. criação do conceito de categoria, ou seja, de grupos profissionais e econômicos organizados consoante desígnios políticos do Estado; d. supressão dos conflitos sociais, em especial das greves, com a instituição da Justiça do Trabalho, dotada de poder normativo.

14. Romita, Arion Sayāo. Direito Sindical Brasileiro, Editora Brasília-Rio, Rio de Janciro, 1976. p. 36 . 
Talvez uma das marcas mais sólidas deixadas foi mesmo a da organização sindical, regulada por legislação ordinária a partir das premissas constitucionais, com as seguintes características: a. unicidade sindical, princípio por meio do qual apenas se admite a constituição de um único sindicato representativo de categoria profissional e econômica, numa determinada base territorial; b. sistema confederativo, em que o sindicato se integra num sistema de relacionamento hierárquico, com federações e confederações, constituídas respectivamente por categorias e ramos de atividade econômica; c. sujeição das entidades sindicais ao Estado, uma vez que cabia ao Ministério do Trabalho não-só o seu registro, mas também a autorização para funcionamento e a fiscalização das atividades, com poderes de intervenção; d. predeterminação das funções a serem exercidas pelos sindicatos, considerados como colaboradores do poder público; e. imposto sindical, cobrado pelo Estado, e destinado à manutenção das entidades sindicais.

Ora, a um sistema como esse se contrapõe o modelo de sindicalismo autônomo, defendido pela Organização Internacional do Trabalho, consoante os princípios de organização sindical estabelecidos em sua Convenção 87

A autonomia é o poder de auto-regulamentação dos próprios interesses. Implica a possibilidade de criação de normas próprias, não-identificáveis com as da ordem estatal. Está relacionada com uma concepção pluralista da sociedade, por meio da qual se admite a existência de vários centros de positivação do Direito.

Obviamente, um sistema de autonomia não se coaduna com a intervenção estatal na vida sindical. Em verdade, caberia ao Estado simplesmente a garantia da liberdade sindical, por meio de normas de sustento das atividades dos sindicatos, que no entanto não-impliquem influência no funcionamento dos mesmos.

A Constituição Federal de 1988 trouxe algum avanço, estabelecendo em seu art. $8^{\circ}$. inciso I, que "a lei não poderá exigir autorização do Estado para a fundação de sindicato, ressalvado o registro no órgão competente, vedadas ao Poder Público a interferência e a intervenção na organização sindical'

Entretanto, não houve um rompimento total com a concepção corporativista, uma vez que restaram alguns de seus traços, como, por exemplo, o princípio da unicidade sindical, o poder normativo da Justiça do Trabalho e o imposto sindical (este último, classificado por Octavio Bueno Magano como um 
"ranço do corporativismo" uma vez que "a contribuição sindical, criada por lei, é um favor que o Estado concede ao sindicato"). ${ }^{15}$

Assim, pode-se concluir o presente estudo afirmando ser indispensável, hoje, a reforma do modelo vigente, partindo do princípio pluralista, consagrado no art. $1^{0}$ da Constituição Federal, que precisa ser irradiado para o campo da organização sindical, de forma a varrer os últimos traços do corporativismo.

Nesse sentido, observe-se essa arguta colocação de Evaristo de Moraes Filho:

"O tóxico corporativista criou uma clara dependência, não-só entre os empregadores, como igualmente entre certas camadas das classes trabalhadoras, que se aconchegaram à proteção dos gabinetes ministeriais. Mas agora, só agora, o movimento social retomou com outras armas e com outro reconhecimento a sua maneira de ser anterior a 1930. Não há conquista sem risco, não há libertação sem rompimento com os laços do paternalismo autoritário. A chamada autonomia privada coletiva retoma seu lugar na elaboração de um direito do trabalho vivo, extra-estatal, nascido diretamente das forças produtivas da sociedade" ${ }^{16}$

São Paulo, agosto de 1999.

\section{Bibliografia}

CARONE, Edgard. A República Velha II (Evolução Política), DIFEL, Rio de Janeiro, 1977.

CESARINO JUNIOR, A. F Direito Social Brasileiro, Editora Saraiva, 1970.

FAUSTO, Boris. A Revolução de 1930, Editora Brasiliense, São Paulo, 1991.

MAGANO, Octavio Bueno. Contribuição confederativa, Anais do CONJUR, FIESP, São Paulo, 1990.

MORAES FILHO, Evaristo de. Introdução ao Direito do Trabalho, Editora LTr, São Paulo, 1986.

15. Magano, Octavio Bueno. Contribuição confederaliva, Anais do CONJUR, FIESP, São Paulo, 1990, p. 19.

16. Moracs Filho, Evaristo de. Ob. cil.. p. 06. 
MUNAKATA, Kazumi. A Legislação Trabalhista no Brasil, Editora Brasiliense, São Paulo, 1981.

NASCIMENTO, Amauri Mascaro. Direito Sindical, Editora Saraiva, São Paulo, 1991.

PAOLI, Maria Célia. A Era do Estado, artigo publicado no Folhetim, caderno do jornal Folha de S. Paulo, 31.12.88.

PIMENTA, Joaquim. Sociologia Econômica e Jurídica do Trabalho, Livraria Freitas Bastos, Rio de Janeiro, 1957

ROMITA, Arion Sayão. Direito Sindical Brasileiro, Editora Brasília-Rio, Rio de Janeiro, 1976.

SKIDMORE, Thomas. Brasil: de Getúlio a Castelo, Paz e Terra, Rio de Janeiro; 1979. 